\title{
Representations about the subject of future activities by students in the classroom profile training
}

\author{
Lyudmila Zheldochenko $^{1^{*}}$ and Nina K. Epritskaya ${ }^{2}$ \\ ${ }^{1}$ Southern Federal University, 344006 Rostov-on-Don, Russian Federation \\ ${ }^{2}$ Irkutsk National Research Technical University
}

\begin{abstract}
The article analyzes the problem of profile education in the modern education system and its role in the pre-profile training of students at the senior level of secondary school. The forms of profile training organization are considered. It is shown that the training of high school students in specialized classes promotes conscious professional choice based on holistic, complete and adequate ideas about the future profession, ideas about their own abilities and professional preferences, contributes to the successful building of an individual educational route. The respondents were senior pupils of specialized and non-specialized classes of secondary schools in the number of 115 people. The following methods were used: "the Questionnaire aimed at studying the ideas about the object of activity (E. I. Rogova), the test method of J. Golland to determine the type of professional orientation of the individual. Methods of mathematical and statistical processing. The results of empirical research of professional representations of senior pupils of educational organizations are presented.
\end{abstract}

\section{Introduction}

Modern reality imposes new requirements for the organization of the learning process in secondary school, including at the senior level of education. Profile training is aimed at the formation of pre-professional competences of students, promotes the development of adequate professional ideas [1]. Profile education in secondary school can be implemented in two forms. The first is the organization of specialized classes within the educational organization, when high school students choose programs of specialized training implemented in the basic school for it. The second is in the form of network interaction, when students are granted the right to receive specialized training in other educational organizations of the same level, or in educational organizations acting as a resource base with sufficient human and material potential [2]. Formed ideas about the future profession are a necessary component of conscious choice of profession, success in professional activity and the key to career growth in the future. High school students are faced with a difficult task of choosing a profession, which is quite difficult to solve on their own. It is obvious that they need the help of teachers in the design and formation of individual

\footnotetext{
${ }^{*}$ Corresponding author: ludmilakateryna@yandex.ru
} 
educational and professional route, in accordance with the inclinations, skills, Hobbies, as well as the requirements of the profession. In this regard, profile training scientists consider as a special form of organization of educational activities, taking into account the individual characteristics of students, contributing to the career guidance of high school students. The researchers note that the advantage of specialized education in professional selfdetermination is reflected in the concept, according to which, the teacher should not only be a professional of the relevant profile, but also contribute to the formation of competencies necessary for high school students to continue their education in the relevant field of future professional activity [3]. According to L.D. Khalikova, the essence of profile training in the system of continuous professional education is the implementation of subject-subject relations necessary for the formation of professional values, identification and development of high school students significant for professional orientation of personality qualities. The author notes that the peculiarity of the organization of profile training at school is associated with the need to create conditions for pre-profile and profile training [4]. N.In. Motorenko in this thesis are experimentally validated the functionality of the system profile orientation of students. According to the author, the creation of the system of profile education of students includes the following elements: variable educational environment, profile content, educational process, career guidance, psychological and pedagogical support, which allows to realize the stated goals of profile education at the level of social and personal to form the necessary basis for continuing education throughout life [5]. According to scientists, the performance of profile training of senior pupils in educational institutions and organizations results in an increase in the level of training in the subjects of basic and profile cycles, improving the performance of individual achievements of students, enhancing motivation and expression of readiness for further education on the chosen profile, satisfaction of high school students, their parents specialized training. They act as a guarantor of personal and professional self-determination of graduates of the profile structure for their further socialization. For the successful profile training of high school students is important to determine the procedural foundations of the educational process at the senior level of the school. As such, there are a set of different tools and activities of students, the conditions for the functioning and implementation of the pedagogical model, as well as the stages of specialized training of high school students. M. V. Sinitsyna, studying the pre-professional differentiation of high school students as a condition for improving the quality of education, notes that education should strive to develop the abilities of students by providing an opportunity to go beyond the information offered by the teacher. The author explains that modern pedagogical science allows to differentiate the learning process, which helps to improve its quality, as it is associated with a more complete provision of educational needs of the individual [6]. The priority of the new educational policy is the quality of education, which is crucially dependent on the interest of students, their plans for the future and awareness of their life prospects. Pre-professional differentiation of students of senior school age on the basis of their life plans and preprofessional intentions has a positive impact on the learning process and contributes to the acquisition of pre-professional competencies. Pre-professional differentiation is a form of organization of educational and cognitive activity of schoolchildren on the basis of their life plans and pre-professional intentions, expressed in the division of students into specialized classes for the purpose of submission and control of the material. Profile training determines the formation of holistic ideas about the future profession, contributes to the clarification of professional choice.

Under professional representations scientists understand a set of images that have reflective, regulatory, motivating, evaluative, prognostic functions and ensure the success of professional activity [7]. 
The representations of the activity performed by the subject are not strictly individual, and since they are usually generated, tested and refined in everyday communication, they can be attributed to a variety of social representations. B. F. Lomov points to the ambivalent nature of professional ideas: on the one hand, they are social, as they are historically conditioned, and on the other - individual, because they tend to reflect the experience and individuality of each individual subject [8]. O. A. Konopkin, says that the idea of professional activity is not just a set of knowledge in any field. According to the author, the idea of activity, which includes: adopted by the subject of the purpose of activity; criteria for the success of activities; program of Executive actions; subjective model of significant conditions of activity; information about the actual results achieved; decisions on corrections of the system of activity [9]. Researchers divided the study of professional ideas about the object of activity and ideas about the professional activity. V. $\mathrm{N}$. Obnosov emphasizes that professional representation is a dynamic information education, the structure and content of which depends on its purpose; it is a reflection of the human " I " through the profession. In addition, as a cognitive-affective mental education has not only information, but also motivational potential for further professional development [10].

\section{Problem statement}

Modern socio-economic development of society imposes strict requirements to the personal and professional qualities of the subject of labor. Today, highly professional and competitive specialists are in demand, ready for continuous self-development and selfimprovement, mobile, able to effectively manage their professional development. The success of professionalization and self-realization largely depends on the correct professional choice at the stage of option, based on adequate professional views. In modern science, the phenomenon of professional ideas is considered and studied in various aspects: the issues of professional orientation of high school students are presented in the studies of L. I. Bozhovich, M. R. Ginzburg, E. F. Zeer, E. A. Klimov, N. S. Pryazhnikov, K. A. Abulkhanova-Slavskaya, S. L. Rubinstein, I. S. Kohn, etc.; the relationship of professional ideas with educational motivation, the dynamics of the development of ideas about the profession at different stages of training are studied in the works of M. V. Naumenko, I. A. Pankratova, E. I. Rogov, etc.. Scientists note that professional self-determination is an important characteristic of the socio-psychological maturity of the individual, its needs for self-realization and self-actualization. The structure of professional ideas scientists represent a three-component, including the idea of the profession and personality of a professional; the idea of yourself as a future professional and the idea of a possible professional future [11].

According to the researches of K. A. Abulkhanova-Slavskaya, professional selfdetermination is considered in inseparable connection with the choice of life path, life selfdetermination. In her opinion, the relationship of personality with profession implies perspective and retrospective personality, and the nature of this relationship depends on the choice of profession [12].

The researchers note that a successful professional choice can be made only by those school graduates whose professional ideas are fully formed, there is an understanding of the correspondence between the requirements of the profession and the abilities of the individual. However, as numerous studies show, less than half of graduates have clear professional ideas, have formed a professional plan and ideas about the trajectory of their professional development[13].

Analysis of the scientific literature showed that accumulated extensive theoretical and empirical material on the problem. So, the problem of profile education received its 
coverage in the papers of M. V. Artyukhova, M. I. Gubanova, L. F. Ivanova, N. And. Kalugin, M. L. Kondrachine, M. V. Levit, P. A. Menshikov, A. A. Pinsky, L. D., Sazonova, etc. the Idea of a differentiated approach to learning is reflected in the writings of Y. I. Ivanov, I. Ya. Lerner, M. V. Lanovoy and other researchers. Works By V. V. Guzeev, O. B. Dautova, O. N. Krylova, P. S. Lerner, I. M. Osmolovskaya, A. P. Tryapitsyna, A.V. The farmhouse is devoted to the development of relevant content and the development of pedagogical technologies. In scientific works by S. N. Belova, I. V. Ilyina, G. N. Podtelkova, S. A. Pisarev, S. N. Chistyakova, A. N. Hudina, T. I. Samovol studied the problems of school management in transition to profile training. However, despite the breadth of research problems, in science there are not enough works devoted to specialized training at the senior level of secondary school.

\section{Purpose of research}

The purpose of this study was to study the professional views of high school students and to identify the features of ideas about the object of future activity in high school students of specialized classes.

\section{Method of research}

In our study, to confirm the hypothesis that the professional views of high school students of specialized classes can be more complete and clear than that of high school students of non-core classes, the following methods were used: "the Questionnaire aimed at studying the ideas about the object of activity (E. I. Rogova), the test method of J. V. Holland to determine personality type. Methods of mathematical and statistical processing. The chosen methods correspond to the tasks of empirical research and provide reliable results.

\section{Description of the study}

The empirical study involved 115 subjects, including 57 high school students of specialized classes and 58 high school students of non-core classes of secondary schools in Rostov-ondon. Among them boys $52 \%$, girls $48 \%$, age limits from 15 to 17 years. The study was conducted in two stages. At the first stage, the theoretical analysis of the problem of profile training at the senior level of secondary school was carried out, the phenomenon of professional ideas in the scientific psychological and pedagogical literature was studied. The selection of diagnostic tools was carried out. Then an empirical study was conducted. First, the types of professional orientation of the personality of high school students of profile and non-profile classes were studied using the test method of J. Holland. The results were statistically processed and analyzed. Then, the ideas about the object of future activity were studied in high school students of specialized and non-core classes using the technique of E. I. Rogov. The results are processed statistically, the analysis of the results, conclusions.

\section{Conclusion}

By results of research of professional orientation of the individual high school core and non-core classes found that the predominant personality type among high school students specialized classes in a lot confirms their professional preferences and select the appropriate profile class in high school. Each of the types of professional orientation of the individual is characterized by certain features, such as: preferences in the choice of 
activities, the ability of the individual to a particular activity, the predominant character traits and the content of Hobbies. It is important to note that each type of professional orientation of the individual corresponds to a certain type of profession. In that case, if a person chooses a profession corresponding to the type of professional orientation of his personality, he can achieve the greatest success in it and get the most satisfaction from work, realize himself fully not only in the professional but also in the personal sphere.

Further, the results of a study of conceptions of high school students core and non-core classes on the subject of their future activities showed that high school students specialized classes the highest severity identified by the factor "evaluation image" - 24 p., then, the degree of severity are indicators of "image force" and 22 p. "activity image" -20 p. and the smallest degree of severity observed for the factor "clarity of image" $19 \mathrm{p}$.

High school non-core classes showed the following results (Table 1): the highest severity identified by the factor "evaluation image" - $21 \mathrm{p}$., then, the degree of severity are indicators of "clarity of image" - 12 p, "image force" 12 p., and the smallest degree of severity observed for the factor "activity image" - $8 \mathrm{p}$.

Table 1. Indicators of the severity of professional views on each factor have high school core and non-core classes (in points).

\begin{tabular}{|l|c|c|c|c|}
\hline \multicolumn{1}{|c|}{$\begin{array}{c}\text { Group of } \\
\text { respondents }\end{array}$} & $\begin{array}{c}\text { "evaluation } \\
\text { image" }\end{array}$ & "image force" & $\begin{array}{c}\text { "clarity of } \\
\text { image" }\end{array}$ & $\begin{array}{c}\text { "activity } \\
\text { image" }\end{array}$ \\
\hline $\begin{array}{l}\text { High school } \\
\text { students of } \\
\text { specialized } \\
\text { classes }\end{array}$ & $24 \mathrm{p}$. & $22 \mathrm{p}$. & $19 \mathrm{p}$ & $20 \mathrm{p}$. \\
\hline $\begin{array}{l}\text { High school } \\
\text { non-core } \\
\text { classes }\end{array}$ & $21 \mathrm{p}$. & $12 \mathrm{p}$. & $12 \mathrm{p}$. & $8 \mathrm{p}$. \\
\hline
\end{tabular}

Therefore, it can be assumed that for high school students of specialized classes are characterized by ideas about the object of activity, consisting in the adoption of the object of future professional activity, they tend to realize it as a carrier of positive, socially desirable characteristics, in a certain sense satisfied with it. High school students of noncore classes are distinguished by lower values for the factor "image evaluation". Such results suggest that high school students of non-core classes are quite critical of the object of their future activities, which is expressed in rejection, their dissatisfaction with his behavior, level of achievement, personality traits. In General, the insufficient level of acceptance of the object of activity is revealed.

According to the factor "image power" high values of high school students of specialized classes speak about the representation of the object of activity as strong-willed, confident and independent, inclined to rely on their own strength in difficult situations. For high school students of non-core classes is characterized by the idea of the object of activity on this factor, as incapable of self-control, unable to keep a certain line of behavior, dependent on external circumstances and assessments, unable to achieve the desired and control the situation.

According to the factor "activity of the image" higher values showed high school students of specialized classes. In their view, the object of future professional activity extroverted, active, responsive, sociable. In contrast, high school students of non-core classes represent the object of activity as introverted, passive, closed, restrained.

For the factor "the clarity of the image" high school students specialized classes showed high values, their ideas about the object of future activities precise enough contrast, 
adequate, bright, in contrast to high school non-core classes, which in the minds ideas about the object of their future activities blurred, fragmented and mosaic.

The Mann-Whitney U-test (Table 2) was used to confirm the assumption that there are significantly significant differences in the values of the factors characterizing the views of high school students of specialized and non-specialized classes about the object of future professional activity and to determine the differences at the level of the studied trait. It is reliably established that there are significant differences in the criteria of "image activity" $(\mathrm{U}=3336.5, \mathrm{p}=0.005)$, the factor of "image clarity" ( $\mathrm{U}=3461.0, \mathrm{p}=0.005)$, and "image strength" $(\mathrm{U}=3202.0, \mathrm{p}=0.001)$.

Table 2. Indicators of the significance of differences in the degree of severity of professional representations in high school students of specialized and non-specialized classes.

\begin{tabular}{|l|c|c|c|}
\hline & "activity image" & $\begin{array}{c}\text { "clarity of } \\
\text { image" }\end{array}$ & "image force" \\
\hline Mann-Whitney U Statistics & 3336,500 & 3461,000 & 3202,000 \\
\hline Statistic Analysis Wilcoxon W & 5334,000 & 5958,500 & 5503,000 \\
\hline Z & $-2,523$ &,- 942 & $-2,093$ \\
\hline Asympt. GNP. (bilateral) &, 005 &, 005 &, 001 \\
\hline
\end{tabular}

In conclusion, it should be noted that specialized training is an important stage of preprofessional training, providing conditions for development of personality of students on the basis of adequate professional representation, allows students at the senior level teaching in secondary schools to develop pre-professional competencies, as well as to know the basics and values of their future profession, to successfully build your individual educational route.

\section{References}

1. L.D. Galdacano, I. E. Rogov, News of Southern Federal University, 12, (2015)

2. V.N. Ramazanova, Profile training of high school students in the network interaction of educational institutions and organizations (Saransk, 2011)

3. L.K. Artemova, Educational and professional route of high school students: from concept to implementation (Kuzgpa, Novokuznetsk, 2008)

4. F.D. Khalikova, Profile training at school as a stage of continuous education: on the example of disciplines of the natural science cycle (Kazan, 2013)

5. N. Motorenko, Vestnik universiteta (GUU), 4, 79-81 (2009)

6. M.V. Sinitsyna, Preprofessional differentiation of high school students as a condition for improving the quality of foreign language teaching (Ekaterinburg, 2003)

7. A.E. Popovich, Secondary vocational education, 3, 36 (2011)

8. B.F. Lomov, Methodological and theoretical problems of psychology (Nauka, Moscow, 1984)

9. O.A. Konopkin, Psychological mechanisms of regulation of activity (Vympel, Moscow 1995)

10. V.N. Obnosov, The idea of the profession as a factor of professional self-determination of vocational school students (Moscow, 1998)

11. E.F. Zeer, Basics of proforientacii, 130 - 154 (2005)

12. K.A. Abulkhanova-Slavskaya, Strategy of life (Thought, Moscow, 1991)

13. E.A. Semenova, Features and formation of professional representations at students in educational space of pedagogical College (Irkutsk, 2003) 